\title{
Attainment of Extremely High Vacuum Using Copper Ultrafine Powder as Cryosorbent in Bakeable-Type Cryopump
}

\author{
Minsheng XU and Yutaka MATSUI \\ ULVAC JAPAN, Ltd., Res. and Dev. Division, 2500 Hagisono, Chigasaki, Kanagawa 253, Japan
}

(Received April 20, 1994, Accepted July 2, 1994)

\begin{abstract}
In order to obtain a clean extremely high vacuum, we made use of copper ultrafine powder ( $\mathrm{Cu}$ UFP) as cryosorbent in bakeable-type cryopumps. Cu UFP was sintered on cryopanels and was cooled to temperatures less than $20 \mathrm{~K}$ to adsorb hydrogen. With use of the cryopumps, their cryopanels could be heated to the temperature of $200^{\circ} \mathrm{C}$, which is effective for desorption of water from Cu UFP during regeneration. From studies on the pumping characteristics as a function of temperature, we found that the Cu UFP cryopanel at temperatures $<20 \mathrm{~K}$ has sufficient pumping capacity for hydrogen released from a well-baked vacuum chamber. After successive bakeouts during regeneration and cryopumping, the test dome was evacuated to a pressure $<10^{-10} \mathrm{~Pa}$ which was maintained for several weeks.
\end{abstract}

\section{Introduction}

A cryopump is considered to be the most promising pump for the production of extremely high vacuum (XHV). In fact, there have been several reports on the attainment of XHV with cryopumps cooled by a closed-loop, gaseous helium refrigerator, which have cryopanels with charcoal adhered to them. ${ }^{1-3)}$ However, the use of charcoal may lead to particle contamination due to fragmentation and contamination of organic molecules as a result of outgassing from epoxy resin used for the adhesion of charcoal to the cryopanel.

For the production of clean vacuum using a cryopump, we adopted ultrafine powder (UFP) of copper as cryosorbent. Although the specific surface area of a commercial Cu UFP $\left(\sim 10 \mathrm{~m}^{2} \mathrm{~g}^{-1}\right)$ is much less than that of charcoal, it is still large enough to adsorb gases released from the wellbaked vacuum chamber for a substantial period as a cryosorbent. Since copper powder can be sintered on a metallic surface in vacuum, we can avoid such contaminations as those of charcoal. In addition, the larger thermal conductivity of metallic material compared to that of charcoal is advantageous for attaining lower temperature and resultant lower equilibrium pressure. A thermal desorption study of the $\mathrm{Cu}$ UFP indicates water desorption at about $200^{\circ} \mathrm{C}$. ${ }^{4)}$ Since the cryopanels in the bakeable-type cryopumps can be heated to the temperature of $200^{\circ} \mathrm{C}$ during regeneration, they are assured of complete regeneration. Since the equilibrium pressure rises with the increase of surface coverage of adsorption, a complete regeneration is essential for the reduction of ultimate pressure in the $\mathrm{XHV}$ region.

In the following sections, we describe the experiment for examining the pumping capability of the cryopanel on which Cu UFP was sintered, the measurements of the pumping speed, and the successful achievements of XHV.

\section{Experiment}

In order to make use of $\mathrm{Cu}$ UFP as cryosorbent in a cryopump, a sintering process on a copper cryopanel was developed for practical use. In Fig. 1 we show a scanning electron microscope (SEM) image of Cu UFP sintered on a copper plate at a temperature of $640^{\circ} \mathrm{C}$ in high vacuum $\left(<1 \times 10^{-3}\right.$ $\mathrm{Pa}$ ) for 4 hours. In the image, a porous structure with scales larger than $1 \mu \mathrm{m}$ was dominant as a result of grain growth by aggregation. Estimated specific surface area of the sintered Cu UFP is on the order of $1 \mathrm{~m}^{2} \mathrm{~g}^{-1} .4$ )

Using cryopumps, we evaluated the pumping characteristics of the cryosorption panel on which $\mathrm{Cu}$ UFP was sintered. The cryopumps adopted for $\mathrm{Cu}$ UFP application are two bakeable-type 


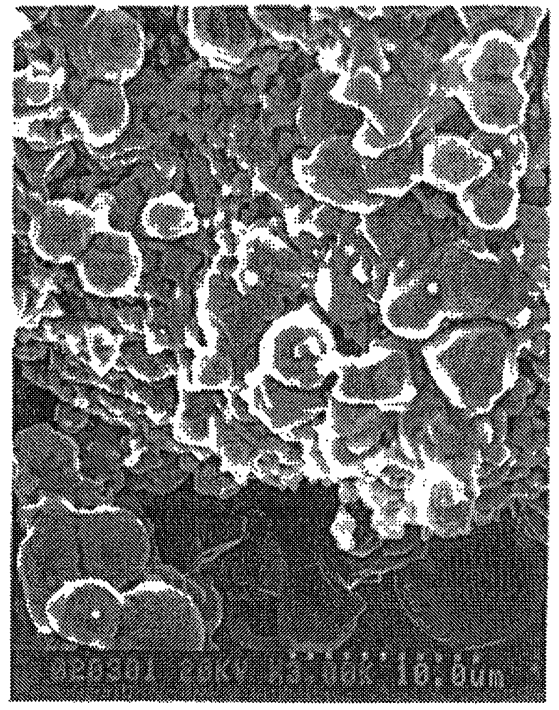

Fig. 1 A SEM image of sintered Cu UFP on a copper plate. The copper powder was sintered at $630^{\circ} \mathrm{C}$ in vacuum at a pressure $<1 \times 10^{-3} \mathrm{~Pa}$.

cryopumps described elsewhere.,5) The first one has three cryopanels, one of which is a cryosorption panel cooled to the temperature of $3-4 \mathrm{~K}$, namely, a $3 \mathrm{~K}$ bakeable-type cryopump. The other is a cryopump which has a $20 \mathrm{~K}$ cryosorption panel, namely, a $20 \mathrm{~K}$ bakeable-type cryopump. The $\mathrm{Cu}$ UFP of $50 \mathrm{~nm}$ diameter from Vacuum Metallurgy Co., Ltd., was sintered onto the cylindrically shaped cryosorption panel instead of adhering charcoal. The cryopanels are made of oxygenfree high-conductivity (OFHC) copper, and glassbead blasting (GBB) was applied on the panel before sintering the Cu UFP. On the $3 \mathrm{~K}$ cryosorption panel, $10 \mathrm{~g}$ of $\mathrm{Cu}$ UFP was sintered, while $30 \mathrm{~g}$ of $\mathrm{Cu}$ UFP was sintered on the $20 \mathrm{~K}$ cryosorption panel. The amount of sintered Cu UFP is approximately proportional to the area of the cryopanel.

For the measurement of pumping speed and ultimate pressure of the cryopump with the Cu UFP cryosorption panel, we placed a test dome on the cryopump. The test dome has a $250 \mathrm{~mm}$ innerdiameter which is the same as that of the opening of the cryopump. To the test dome, we connected the gas inlet system through an orifice. The gas inlet system consisted of a reservoir with a turbomolecular pump (TMP), a mass flowmeter and a gas bottle. A schematic drawing of the system is shown in Fig. 2. Roughing was performed separately on the test dome/cryopump system and on the reservoir by independent TMPs. The chamber and pipes were made of SS304 stainless steel. The final pressure was measured after removing the gas inlet

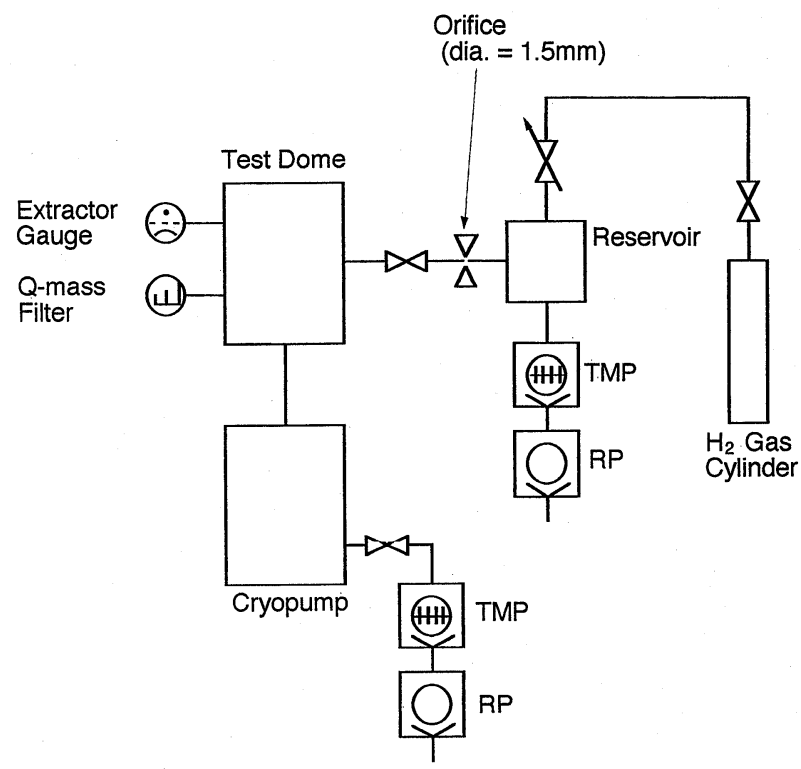

Fig. 2 Schematic diagram of the vacuum system to measure pumping speed and ultimate pressure of the cryopump. The ultimate pressure measurement was performed by removing the gas inlet system including the reservoir. The test dome is a cylinder with an opening diameter of $250 \mathrm{~mm}$ and height of $375 \mathrm{~mm}$, and the reservoir is a 60 -mm-diam., 150-mm-high cylinder. 


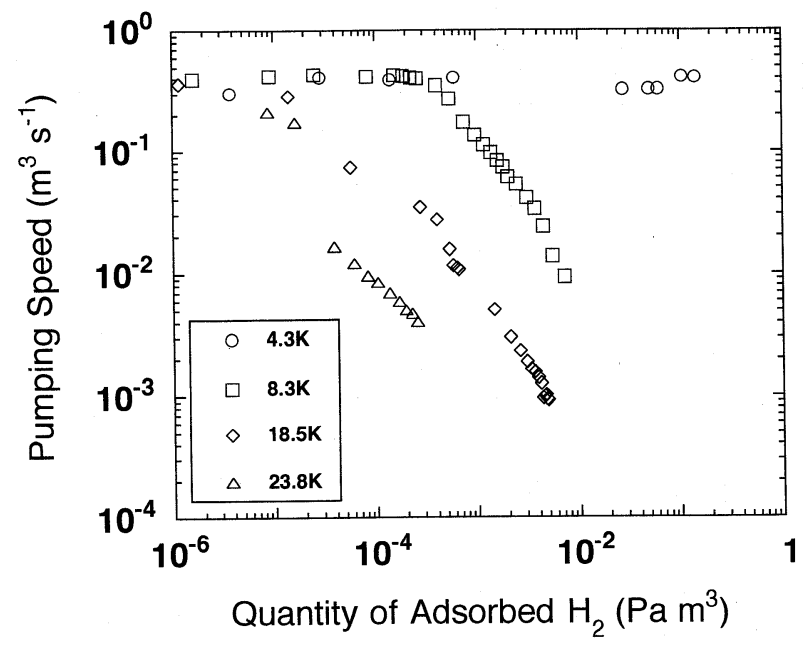

Fig. 3 Pumping speed of the cryopump with $\mathrm{Cu}$ UFP for hydrogen vs quantity of adsorbed $\mathrm{H}_{2}$. Temperature of $\mathrm{Cu}$ UFP panel was measured by a silicon diode sensor and was adjusted by opening the JT valve. The temperature of the panel was kept at $4.3,8.3,18.5$ or $23.8 \mathrm{~K}$ during the period of measurement.

system. For the measurement of the total pressure, we used an extractor gauge (IE514 of Leybold Heraeus), and a quadrupole mass filter was also attached to the test dome for residual gas analysis.

\section{Hydrogen Pumping Speed of Cryopump with Cu UFP}

Since the cryopump is a capturing pump, pumping speed depends on the amount of gas adsorbed. We measured the pumping speed of the $3 \mathrm{~K}$ cryopump with $\mathrm{Cu}$ UFP with respect to quantity of adsorbed hydrogen by varying the temperature. The temperature of the panel with Cu UFP was measured with a silicon diode sensor. By adjusting the Joule-Thomson (JT) valve of the refrigeration system, we could vary the temperature from 4.3 to $23.8 \mathrm{~K}$ while keeping the temperature of the other cryopanels essentially constant. The reservoir was pumped down to the pressure of $10^{-8} \mathrm{~Pa}$ by a TMP before introducing hydrogen gas. Between the reservoir and the test dome, we placed an orifice with a conductance of $5.8 \times 10^{-4} \mathrm{~m}^{3} \mathrm{~s}^{-1}$ for $\mathrm{H}_{2}$ at $20^{\circ} \mathrm{C}$. By regulating the flow of hydrogen into the reservoir, we could control the pressure in the reservoir and the flow rate into the test dome. For the measurement of pumping speed, we recorded the pressures in the reservoir and in the test dome simultaneously. The throughput into the test dome was derived from the difference of the pressures and the conductance of the orifice. We show the variation of pumping speed with respect to the amount of adsorbed hydrogen in Fig. 3. During the measurement, the pressure in the reservoir changed from $2 \times 10^{-6} \mathrm{~Pa}$ to $10^{-3} \mathrm{~Pa}$, and the pressure in the test dome varied from $2 \times 10^{-9} \mathrm{~Pa}$ to $10^{-5} \mathrm{~Pa}$. On the other hand, the outgassing rates from the test dome and the cryopump housing were estimated to be on the order of $10^{-10} \mathrm{~Pa} \mathrm{~m}^{3}$ $\mathrm{s}^{-1}$ from the measurement of outgassing rate from the pump housing. ${ }^{\text {) }}$ Therefore outgassing rate is negligible compared to the throughput of hydrogen.

The observed initial pumping speed, $0.4 \mathrm{~m}^{3} \mathrm{~s}^{-1}$, was close to the value of a cryopanel with charcoal adhered to it and was limited by the conductance through the panel/baffle system. Figure 3 clearly shows a decreasing trend of pumping speed due to saturation of hydrogen adsorption for the cryopanel, except for the case at $4.3 \mathrm{~K}$. The $\mathrm{Cu}$ UFP panel cooled to the temperature of $4.3 \mathrm{~K}$ had a pumping capacity of at least $0.2 \mathrm{~Pa} \mathrm{~m}^{3}$, which indicates that practical use for cryo-pumping is possible. We inferred based on Fig. 3 that a Cu UFP cryopanel, even at about $20 \mathrm{~K}$, is capable of pumping a vcuum chamber with a high-vacuum roughing pump such as a TMP.

\section{Pumping-Down Processes to the Pressure of $10^{-10} \mathrm{~Pa}$}

Upon the installation of the cryosorption panel with $\mathrm{Cu}$ UFP in the $20 \mathrm{~K}$ bakeable-type cryopump, which has cryopanels at similar temperatures to those of a conventional refrigerator cryopump, we investigated the ultimate pressure of the pump. 


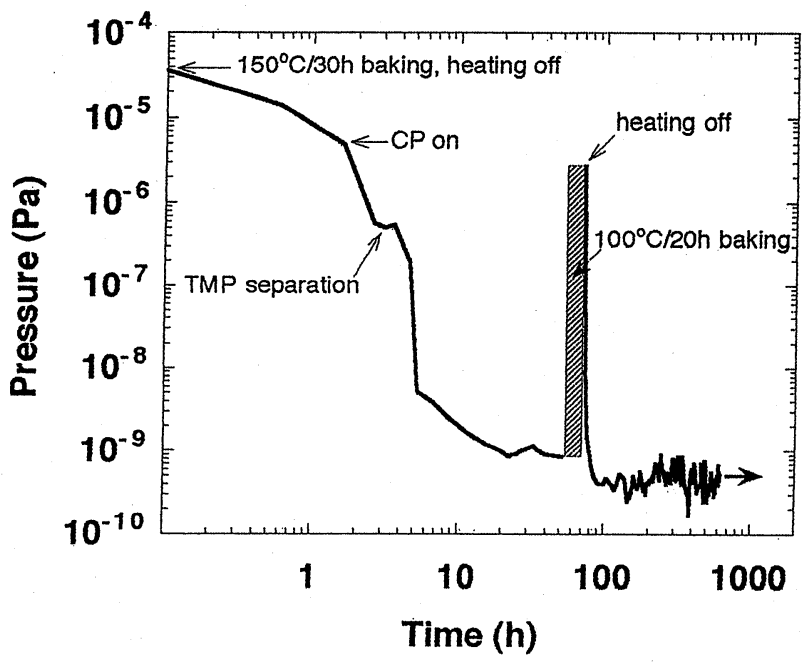

Fig. 4 The first pump-down process to $10^{-10} \mathrm{~Pa}$. The time in the figure indicates time elapsed after the completion of $150^{\circ} \mathrm{C}, 30 \mathrm{~h}$ bakeout of the test dome/cryopump system during regeneration. After $80 \mathrm{~h}$ of pumping, the pressure in the test dome dropped to the range of $10^{-10} \mathrm{~Pa}$.

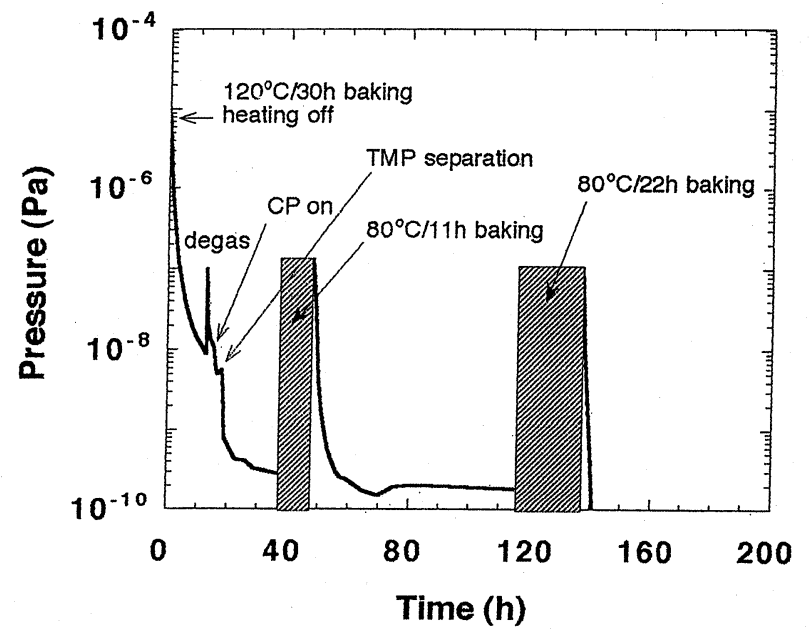

Fig. 5 The second pump down process to a pressure $<1 \times 10^{-10} \mathrm{~Pa}$, i.e., XHV. The time in the figure indicates time elapsed after the completion of heating the system at $120^{\circ} \mathrm{C}$ for $30 \mathrm{~h}$. After two mild bakeouts at $80^{\circ} \mathrm{C}$, pressure in the test dome and cryopump system was reduced to a value less than $1 \times 10^{-10} \mathrm{~Pa}$.

For the first experiment, a $50 \mathrm{l} / \mathrm{s}$ TMP was adopted as a roughing pump during regeneration. The pumping-down curve of the test dome is shown in Fig. 4. After a $150^{\circ} \mathrm{C}$ bakeout for $30 \mathrm{~h}$, the pressure of the system decreased to $3 \times 10^{-6} \mathrm{~Pa}$ with the TMP only. Then, turning on the refrigerator system of the cryopump, the pressure in the test dome decreased to $8 \times 10^{-8} \mathrm{~Pa}$ in $20 \mathrm{~h}$. For further reduction of the pressure, we applied a $100^{\circ} \mathrm{C}$ bakeout for $20 \mathrm{~h}$, and obtained an ultimate pressure of 2-
$4 \times 10^{-10} \mathrm{~Pa}$. The pressure remained in the range of $10^{-10} \mathrm{~Pa}$ for three weeks until we discontinued the pumping process.

In order to reduce the pressure at which cryopumping starts, we replaced the $50 \mathrm{l} / \mathrm{s}$ TMP with a $300 \mathrm{l} / \mathrm{s}$ TMP. During the replacement, the test dome/cryopump system was aerated for one day. In this case, the system was evacuated to the pressure of $1 \times 10^{-8} \mathrm{~Pa}$ after bakeout, by pumping with the $300 l / \mathrm{s}$ TMP (Fig. 5). Then the cooling sys- 
tem of the cryopump was turned on for further pumping. When the cryopanels were completely cooled, the pressure in the test dome was reduced to $3 \times 10^{-10} \mathrm{~Pa}$. Then, by carrying out two mild baking procedures $-80^{\circ} \mathrm{C}$ for $11 \mathrm{~h}$ and $80^{\circ} \mathrm{C}$ for $22 \mathrm{~h}$-while continuing the evacuation with the cryopump, the pressure in the test dome was lowered to a value less than $1 \times 10^{-10} \mathrm{~Pa}$ when the temperature of the test dome/crypump system returned to room temperature.

\section{Summary}

By sintering $\mathrm{Cu}$ UFP in high vacuum on a cryopanel, we built a cryopump which is free from particle and organic contamination. The measurement of pumping speed of the cryopump with respect to quantity of adsorbed hydrogen indicates that the cryosorption panel with Cu UFP can be used for pumping of a vacuum chamber with the help of a high-vacuum roughing pump. The sintered Cu UFP functioned successfully as a cryosorbent in the refrigerator-cooled $20 \mathrm{~K}$ cryopump for the production of extremely high vacuum with the help of a roughing TMP.

\section{References}

1) T. Kikuchi, N. Ohsako and Y. Hayashi: Vacuum, 41 (1989) 1941.

2) Y. Matsui, K. Yui and H. Yamakawa: J. Vac. Sci. Technol., A9 (1991) 2010.

3) Y. Matsui, H. Ohzora and H. Yamakawa: J. Vac. Sci. Technol., A11 (1993) 422.

4) Y. Sakka, T. Uchikoshi and E. Ozawa: Materials Transactions JIM, 31 (1990) 802.

5) H. Yamakawa, Y. Matsui, K. Yui and H. Yanagida: Vacuum, 41 (1990) 1837.

6) T. Arai, K. Takeuchi, Y. Tuzi, Y. Matsui, H. Yamakawa and T. Okano: J. Vac. Soc. Jpn. (Shinku), 36 (1993) 245. 